\title{
Revisão das Diretrizes da ABENO para a definição do Estágio Supervisionado Curricular nos cursos de Odontologia
}

Ana Isabel Fonseca Scavuzzi*; Cresus Vinícius Depes de Gouveia**; Daniela Lemos Carcereri***; Elaine Bauer Veeck****; José Ranali*****; Lino João da Costa******; Maria Celeste Morita*******; Maria Ercília de Araújo $* * * * * * * *$

* Professora Titular da Universidade Estadual de Feira de Santana; Coordenadora do Curso de Odontologia da Unime Lauro de Freitas; Presidente da Comissão de Ensino da Associação Brasileira de Ensino Odontológico - ABENO.

** Professor Titular da Universidade Federal Fluminense; Presidente do Colegiado Gestor da Faculdade de Odontologia de Nova Friburgo; Membro da Comissão de Ensino da Associação Brasileira de Ensino Odontológico - ABENO.

*** Coordenadora do Curso de Graduação em Odontologia da Universidade Federal de Santa Catarina; Membro da Comissão de Ensino da Associação Brasileira de Ensino Odontológico - ABENO.

**** Professora Titular da Pontifícia Universidade Católica do Rio Grande do Sul; Membro da Comissão de Ensino da Associação Brasileira de Ensino Odontológico ABENO.

***** Professor Titular da UNICAMP; Membro da Comissão de Ensino da Associação Brasileira de Ensino Odontológico - ABENO.

****** Professor Associado da Universidade Federal da Paraíba; Membro da Comissão de Ensino da Associação Brasileira de Ensino Odontológico - ABENO.

$* * * * * * *$ Professora Associada da Universidade Estadual de Londrina; Presidente da Associação Brasileira de Ensino Odontológico - ABENO.

******** Professora Titular da Faculdade de Odontologia da Universidade de São Paulo; Membro da Comissão de Ensino da Associação Brasileira de Ensino Odontológico - ABENO.

\section{RESUMO}

O estágio curricular supervisionado é objeto de lei e de avaliação dos cursos de graduação em Odontologia pelo Ministério da Educação do país. A regulamentação deste componente curricular é amparada por diferentes segmentos de regulação da formação profissional do cirurgião dentista. A Associação Brasileira de Ensino Odontológico (ABENO) por meio da sua Comissão de Ensino divulgou as primeiras diretrizes acerca do assunto em 2002 e apresenta a revisão destas diretrizes à luz da legislação vigente e das melhores práticas educacionais para atendimento ao perfil do egresso preconizado pelas Diretrizes Curriculares Nacionais (DCN) para o curso de graduação em Odontologia. Assim, são apresentadas 12 diretrizes da ABENO para a 
definição do estágio curricular supervisionado nos cursos de graduação em Odontologia.

Descritores: Estágio. Odontologia. Educação em Saúde

\section{INTRODUÇÃO}

A Comissão de Ensino da Associação Brasileira de Ensino Odontológico (ABENO), a partir da legislação vigente pertinente ao assunto, apresenta a revisão das Diretrizes da ABENO para a definição do estágio supervisionado curricular publicada em $2002^{1}$.

De acordo com a Lei $n^{\circ} 11788$, de 25 de setembro de 2008, publicada no Diário Oficial da União em 26/09/2008 (2008) ${ }^{2}$ no seu artigo primeiro define:

"Estágio é ato educativo escolar supervisionado, desenvolvido no ambiente de trabalho, que visa à preparação para o trabalho produtivo de educandos que estejam frequentando o ensino regular em instituições de educação superior, de educação profissional, de ensino médio, da educação especial e dos anos finais do ensino fundamental, na modalidade profissional da educação de jovens e adultos.

$\S 1^{\circ}$ O estágio faz parte do projeto pedagógico do curso, além de integrar o itinerário formativo do educando.

$\S 2^{\circ} \mathrm{O}$ estágio visa ao aprendizado de competências próprias da atividade profissional e à contextualização curricular, objetivando o desenvolvimento do educando para a vida cidadã e para o trabalho".

E ainda no artigo $9^{\circ}$ da Lei $n^{\circ} 11788^{2}$ : "As pessoas jurídicas de direito privado e os órgãos da administração pública direta, autárquica e fundacional de qualquer dos Poderes da União, dos Estados, do Distrito Federal e dos Municípios, bem como profissionais liberais de nível superior devidamente registrados em seus respectivos conselhos de fiscalização profissional podem oferecer estágio", observadas as obrigações descritas nesta mesma $\operatorname{Lei}^{2}$ (2008).

No artigo sétimo das Diretrizes Curriculares Nacionais para o curso de graduação em Odontologia - $\mathrm{DCN}^{3}$ : “ $A$ formação do Cirurgião Dentista deve garantir o desenvolvimento de estágios curriculares, sob supervisão docente. Este estágio deverá ser desenvolvido de forma articulada e com complexidade crescente ao longo do processo de formação. A carga horária mínima do estágio curricular supervisionado deverá atingir 20\% da carga horária total do Curso de Graduação em Odontologia proposto, com base no Parecer/Resolução específico da Câmara de Educação Superior do Conselho Nacional de Educação (2007)" 4 .

A consolidação das Normas para procedimentos nos Conselhos de Odontologia ${ }^{5}$ (2013) define no Capítulo VII - Estágio de Estudante de Odontologia, artigo 31: "As atividades do estágio curricular poderão ser realizadas na comunidade em geral ou junto a pessoas jurídicas de direito público ou privado, sob a responsabilidade e coordenação direta de cirurgião-dentista professor da instituição de ensino superior (IES) em que esteja o aluno matriculado, atendidas as exigências contidas no artigo $5^{\circ}$, do Decreto 87.497, de 18 de agosto de 1982".

$\mathrm{O}$ indicador 2.19 do Instrumento de Avaliação de Cursos de Graduação $^{6}$ do Ministério da Educação (2015) instituído de acordo com a Lei no. $10.861^{7}$ do SINAES (2004) trata da responsabilidade docente pela assistência odontológica, apresentando critérios para a avaliação deste componente pela comissão avaliadora quando da visita in loco de avaliação dos cursos de graduação em Odontologia. 


\section{DIRETRIZES DA ABENO PARA O ESTÁGIO CURRICULAR}

\section{Quanto aos cenários e atividades do estágio supervisionado}

\section{Diretriz 1:}

Ambiente de trabalho é o local no qual são desenvolvidas atividades relacionadas diretamente às competências gerais e específicas de um cirurgião-dentista. Este ambiente é configurado por serviços de saúde inseridos no mundo do trabalho, providos de profissionais de saúde que compõem o quadro de pessoal, realizando atividades com grupo de indivíduos (ações coletivas), com pacientes (assistência individual) e de gestão. A flexibilização dos cenários intramurais e extramurais e das atividades permitirá que cada curso discuta suas opções e as coloquem em prática de acordo com o Projeto Pedagógico do Curso (PPC) e a obtenção do perfil do egresso almejado.

\section{Diretriz 2:}

$\mathrm{O}$ estágio deve permitir que a experiência profissional desenvolvida ao longo de suas atividades possibilite ao estudante o reconhecimento da realidade social, do funcionamento dos serviços de saúde, articule a teoria com a prática em situação real e cotidiana, conheça a realidade do mercado de trabalho e se aproprie da lógica do sistema de saúde, em todas as suas dimensões. Fomentar a relação ensino-serviço e ampliar as relações da IES com a sociedade, colocando o futuro profissional em contato com as diversas realidades sociais (locais, regionais e nacionais), incluindo as práticas e políticas em saúde coletiva e a realidade do mercado de trabalho devem ser os grandes objetivos do estágio curricular.

\section{Diretriz 3:}

O Sistema Único de Saúde (SUS) deve ser compreendido como o efetivo ordenador da formação de recursos humanos na área da Saúde. A articulação com o SUS deve ser regulada por meio de Contrato Organizativo ou convênio entre as Instituições públicas e a IES, trabalhando na perspectiva de parceria interinstitucional, para que o fluxo de referência e contra referência possa ser sistematizado e valorizado por ambas as partes. A integração ensino-serviço público de saúde exercido nas atividades de promoção, prevenção de agravos, reabilitação da saúde deve enfatizar o processo de trabalho em equipe multiprofissional e interdisciplinar, atendendo o princípio da integralidade de atenção à saúde no SUS.

\section{Diretriz 4:}

O estágio intra e extramural nas clínicas integradas de atenção básica com complexidade crescente, onde os alunos executam competências já adquiridas, desenvolvendo atividades de educação e promoção de saúde até à reversão do dano são considerados cenários de estágio do curso de Odontologia, desde que o estudante realize a atenção básica resolutiva, contemplando o atendimento integral ao paciente.

\section{Diretriz 5:}

Atuação nas clínicas intramurais, ambulatórios, hospitais e outros espaços de desenvolvimento de atividades de promoção de saúde, prevenção de doença, assistência e recuperação da saúde próprios das IES são cenários do estágio somente nas situações em que houver alguma relação com o SUS, comprovada por meio de convênio e agenda 
integrada, viabilizando o estabelecimento de fluxo para referência e contra referência.

\section{Quanto à composição da carga horária do estágio supervisionado}

\section{Diretriz 6:}

A carga horária do estágio curricular correspondente a $20 \%$ da carga horária total do curso não substitui a carga horária em atividades práticas que envolvem $\mathrm{o}$ atendimento de pacientes, exigida para o desenvolvimento das competências e habilidades clínicas específicas de cada disciplina. As clínicas isoladas de uma, duas ou três especialidades e as aulas práticas laboratoriais não são consideradas para efeito de estágio supervisionado.

\section{Diretriz 7:}

O cumprimento de $100 \%$ da carga horária total dos estágios nos diversos espaços do SUS como cenários de aprendizagem é considerado a condição ideal desejável.

\section{Diretriz 8:}

Alternativamente, é suficiente que no mínimo $50 \%$ da carga horária total do estágio curricular deverão ser desenvolvidas fora do âmbito intramural da instituição e, da carga horária extramural que corresponderia a $50 \%$ no mínimo metade (25\%) deverá ser obrigatoriamente desenvolvida no SUS.

\section{Quanto à supervisão do estágio}

Diretriz 9:

Entende-se por ato educativo supervisionado o desenvolvimento de atividades que aperfeiçoem o aprendizado do aluno sob a responsabilidade e coordenação direta de professor cirurgião-dentista da instituição de ensino, que desempenhe a supervisão direta e desenvolva sua capacidade de proporcionar a construção do conhecimento, em especial pelo estímulo a práticas de estudo independente, visando uma progressiva autonomia intelectual e profissional do aluno.

\section{Diretriz 10:}

A articulação da área da educação com a área da saúde deve contribuir para a efetiva transformação dos serviços públicos em campos efetivos de estágio, com capacitação de preceptores no campo de estágio e professores da IES baseado na ciência e na realidade dos serviços, estimulando a formulação de referencial epidemiológico em saúde bucal na região da IES, possibilitando o estabelecimento de metas comuns para o serviço de saúde e para o curso de Odontologia.

\section{Diretriz 11:}

Para o estágio curricular é obrigatório o acompanhamento e orientação efetivos presenciais in loco por um docente do curso de Odontologia da própria IES, sendo a relação entre o número de estudantes e docentes, no mínimo, suficiente, ou seja, um docente para 12 (doze) alunos. A supervisão e coordenação do estágio devem estar previstas no regulamento do estágio supervisionado da IES.

\section{Diretriz 12:}

Deve-se buscar o enfrentamento da dicotomia entre os professores do campo de conhecimento da saúde coletiva e do campo de conhecimento da clínica por meio da discussão sobre a determinação do processo saúde doença, apoiando-se no desenvolvimento de competências para lidar com a coletividade e identificação das redes de atenção à saúde. 


\section{CONCLUSÕES}

O estágio curricular supervisionado é um componente curricular obrigatório para os cursos de graduação em Odontologia e a sua definição deve estar respaldada, descrita com o detalhamento necessário ao acompanhamento como atividade de ensino, supervisionado em todas as etapas de desenvolvimento e distinto de outras atividades curriculares práticas de ensino necessárias à formação do cirurgião dentista.

\section{AGRADECIMENTOS:}

Prof. Dr. Leo Kriger, Prof. Dr. Luiz Roberto Augusto Noro e Profa. Dra. Ana Estela Haddad, pelas contribuições.

\section{REFERÊNCIAS}

1. Diretrizes da ABENO para a definição do estágio supervisionado nos cursos de Odontologia. Rev ABENO 2002; 2(1):39.

2. Brasil. Lei $\mathrm{n}^{\circ} .11788$, de 25 de setembro de 2008. Dispõe sobre estágio de estudantes. Diário Oficial da União 26 dez 2008.

3. Ministério da Educação. Conselho Nacional de Educação. Câmara de Educação Superior (Brasil). Resolução ${ }^{\circ}$ 3, de 19 de fevereiro de 2002. Diretrizes Curriculares Nacionais do Curso de graduação em Odontologia.

4. Ministério da Educação. Conselho Nacional de Educação. Câmara de Educação Superior (Brasil). Resolução no 2, de 18 de junho de 2007. Dispõe sobre carga horária mínima e procedimentos relativos à integralização e duração dos cursos de graduação, bacharelados, na modalidade presencial. Diário Oficial da União 16 jun 2007; Edição 116.

5. Conselho Federal de Odontologia (Brasil). Resolução 63/2015, atualizada em julho de 2013. Consolidação das Normas para
Procedimentos nos Conselhos de Odontologia. Diário Oficial da União 19 abr 2015; Seção I.

6. Ministério da Educação do Brasil. Instrumento de Avaliação de Cursos de Graduação: presencial e à distância, do Sistema Nacional de Educação Superior SINAES. Agosto 2015.

7. Brasil. Lei ${ }^{\circ} 10.861$, de 14 de abril de 2004. Institui o Sistema Nacional de Avaliação da Educação Superior - SINAES e dá outras providências. Diário Oficial da União 15 abr 2004; p.3.

\section{ABSTRACT \\ ABENO's review of the Guidelines to define the Supervised Curricular Internship in Dental courses}

The supervised traineeship is a law object in the evaluation of Dental undergraduate courses in Brazil, by the country's Ministry of Education. The regulation of this curricular component exists in several documents provided by different segments of regulating the training of dentists. The Brazilian Association of Dental Education (Associação Brasileira de Ensino Odontológico - ABENO), through its Education Commission, issued the first guidelines on this subject in 2002, and presents a review of these guidelines in the light of current legislation and best educational practices to meet the profile of the recommended egress by the Guidelines National curriculum for undergraduate Dental course. Thus, they present 12 ABENO guidelines for the definition of curricular supervised training in undergraduate courses in dentistry.

Descriptors: Internships. Dentistry. Health Education

Correspondência para

Profa. Dra. Ana Isabel Fonseca Scavuzzi e-mail: anaisabel.fonseca@outlook.com Av. Magalhães Neto, 1795, apto. 703 - Pituba 41810-011 - Salvador - BA 